\title{
EVOLUTION OF BIOLOGICAL COMPLEXITY: A CASE STUDY OF AMMONOID SUTURES
}

BOYAJIAN, George E., Department of Geology, University of Pennsylvania, 240 S. 33rd Street, Philadelphia PA 19104-6316 U.S.A.; LUTZ, Tim, Department of Geology \& Astronomy, West Chester State University, West Chester PA 19383 U.S.A.

The evolution of ammonoid sutures has long been cited as an example of the evolution of increased biological complexity. The complexity of sutures has increased, on average, but the exact nature of this increase, and any benefit associated with this increase has yet to be documented. We measure the fractal dimension of $>600$ ammonoid species and document the change in complexity of sutures between and among seven orders: Ammonitida, Anarcestida, Ceratitida, Clymeniida, Goniatitida, Phylloceratitida, and Prolecanitida. The average complexity of sutures and range of complexity of sutures increased from the Devonian to the Triassic. With the rise of the Ammonitida, average complexity of sutures remained constant or dropped slightly through the Mesozoic. However, the simplest sutures continue to originate over that same interval. The evolution of increased complexity is the result of increased number of complex forms, not selective loss of simple ones. (See figure 1)

We then compare the stratigraphic ranges (longevity) of a genus with the fractal dimension of a member of the genus. Increased sutural complexity does not significantly increase or decrease the susceptibility of a genus to extinction. In other words, there is no differential survival among simple and complex forms. We also show that in ancestor-descendant pairs, descendants do not demonstrate a propensity to become either more complex or more simple than their ancestors. These observations suggest that it may be difficult to demonstrate that the evolution of biological complexity is the result of natural selection. Increased complexity may be the result of experimentation with other anatomical features or the result of an evolutionary random walk.

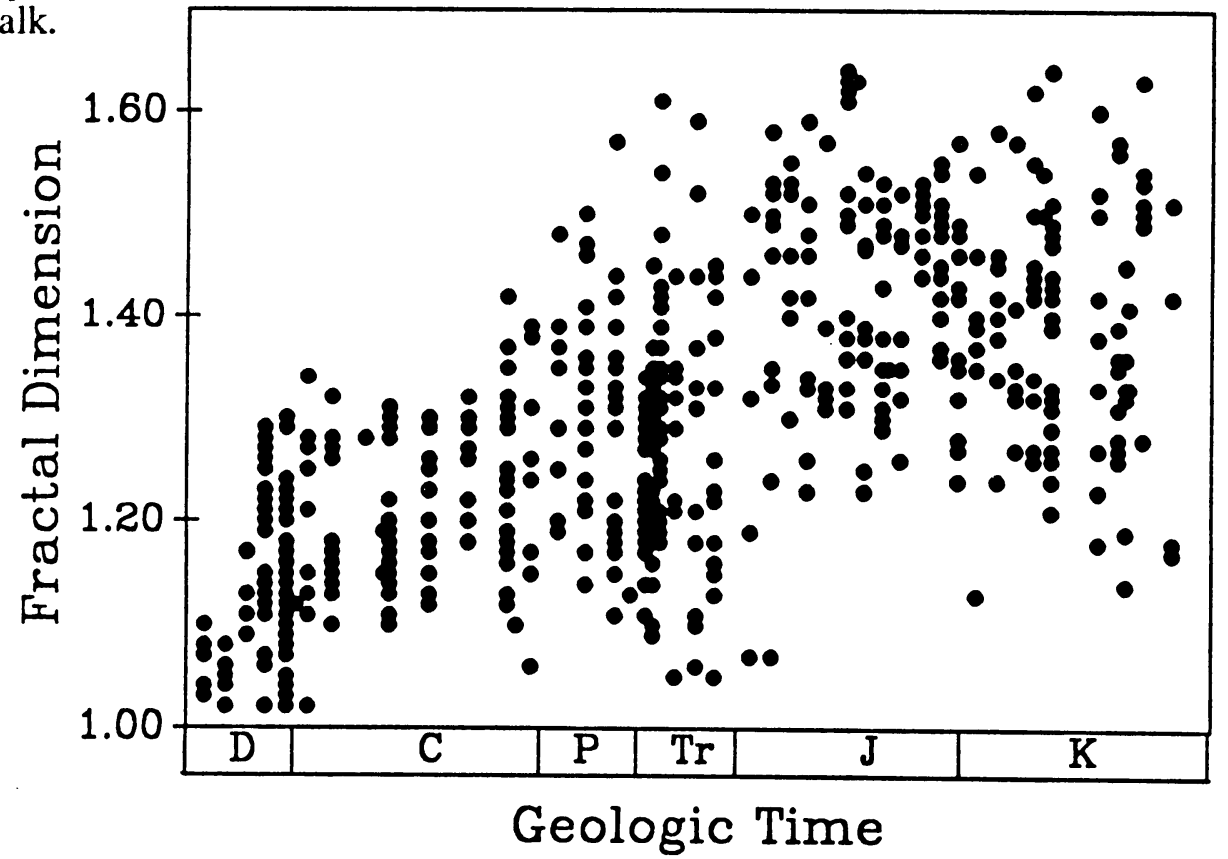

Figure 1. The fractal dimension of $>600$ ammonoid genera plotted at the time of their origination. 